\title{
Validation of Rosmarinic Acid Quantification using High- Performance Liquid Chromatography in Various Plants
}

\author{
Andiri Niza Syarifah ${ }^{1}$, Herman Suryadi ${ }^{2, *}$, Abdul Mun'im ${ }^{3}$
}

\section{Andiri Niza Syarifah', Herman Suryadi ${ }^{2, *}$, Abdul Mun'im ${ }^{3}$}

${ }^{1}$ Faculty of Pharmacy, Universitas Indonesia, 16424, Depok, INDONESIA

${ }^{2}$ Department of Bioavailability and Bioequivalence Laboratory, Faculty of

Pharmacy, Universitas Indonesia, 16424, Depok, INDONESIA.

${ }^{3}$ Department of PharmacognosyPhytochemistry, Faculty of Pharmacy, Universitas Indonesia, 16424, Depok, INDONESIA.

\section{Correspondence}

\section{Herman Suryadi}

Department of Bioavailability and Bioequivalence Laboratory, Faculty of Pharmacy, Universitas Indonesia, 16424

Depok, INDONESIA

Phone no: +628111184550

E-mail: hsuryadi@farmasi.ui.ac.id

History

- Submission Date: 10-11-2021.

- Review completed: 29-11-2021;

- Accepted Date: 03-12-2021.

DOI : 10.5530/pj.2022.14.22

Article Available online http://www.phcogj.com/v14/i1

\section{Copyright}

(C) 2022 Phcogi.Com. This is an openaccess article distributed under the term of the Creative Commons Attribution 4.0 International license.

\begin{abstract}
Introduction: Rosmarinic acid has been utilized in traditional medicine as antioxidant, antiinflammation, anticancer and antibacterial. In order to control the herbal quality, validation of rosmarinic acid determination using high-performance liquid chromatography was developed. The objective of this report was to validate an HPLC technique for assessing rosmarinic acid levels. and application that method to determine rosmarinic acid in Rosmarinus officinalis, Symphytum officinale, Mentha piperita, Orthosiphon stamineus and Salvia officinale. Methods: The chromatographic separation was carried out on a reversed-phase C18 column with a mobile phase of $0,1 \%$ formic acid and acetonitrile and an isocratic elution at a flow rate of 0,5 $\mathrm{mL} / \mathrm{min}$. The wavelength for detection was set to $330 \mathrm{~nm}$. The method has been validated for precision, accuracy, linearity, limit of detection, and limit of quantitation. Result: The concentration response of the detector was linear, with a coefficient of determination of 0.9933 . The HPLC technique had an accuracy of $101,00 \pm 6,43 \%$. The precision was $6,36 \%$ when expressed as a coefficient of variation (CV). The highest level of rosmarinic acid was $214,86 \pm 0,60 \mu \mathrm{g} / \mathrm{mL}$ in Rosmarinus officinalis extract. Conclusion: The HPLC method was valid to analyse rosmarinic acid level. The method can be applied in routine determination of rosmarinic acid of phytopharmaceutical products.
\end{abstract}

Key words: Rosmarinic acid, HPLC, Laminaceae Borraginaceae.

\section{INTRODUCTION}

Some secondary metabolites of plants have numerous health benefits such as polyphenols. Polyphenols was found in variety plants and has therapeutic effects ${ }^{1,2}$. Previous study reported the phenolic compounds have antioxidant, antiinflammation and antibacterial activity ${ }^{3-5}$. Rosmarinic acid is one of the most typical phenolic compounds. As the caffeic acid ester of 3,4-dihydroxyphenyllactic acid, rosmarinic acid is a phenylpropanoid. ${ }^{6,7}$.

Rosmarinic acid was reported occurs in Boraginaceae and Lamiaceae plant families ${ }^{8,9}$. One of Boraginaceae family was Symphytum officinale, commonly known as Comfrey. Rosmarinic acid level in Symphytum officinale was 7,557 $\pm 0,005 \mathrm{mg} / \mathrm{g}$ in comfrey root sample ${ }^{3,10}$. Rosmarinus officinalis L. (Lamiaceae), also known as rosemary, is a herb that is utilized all over the world. Rosemary extract also contains a significant amount of phenolic chemicals, such as rosmarinic acid ${ }^{11,12}$. Peppermint (Mentha piperita) is a Lamiaceae herbaceous plant with a global distribution. Mentha species dried leaves have been used as a herbal tea and as a primary element in several pharmacological formulations with multiple health benefits in cooking as a herb for centuries 5 . Orthosiphon stamineus, the java tea plant, is widely grown throughout Southeast Asia, Australia, and southern China. It has been used as a tea in South Asia for thousands of years, and it's also a popular traditional Chinese medicinal herb for kidney stones ${ }^{13}$. There were substantial changes in the composition of phenolic extracts from different Salvia species, and the phenolic extracts of Salvia officinalis L. demonstrated considerable scavenging action of active oxygen, such as superoxide anion radicals, hydroxyl radicals, singlet oxygen, and lipid peroxides. The results show that the efficacy is due in part to the presence of phenolic acids, specifically rosmarinic acid, which has been found in large amounts in a number of therapeutic plants. ${ }^{6}$.

On the previous study, rosmarinic acid was determined using gradient HPLC method, LC/ MS/MS, spectrophotometry method and Fourier transform infrared ${ }^{3,6,14}$. HPLC is a simple and reliable methods for routine analysis and easily used for quantification of individual compounds. Most of research to determine rosmarinic acid used gradient HPLC. Although HPLC separation has been reported for calculation of rosmarinic acid in some plants, a fast, simple and valid analytical method is needed. Therefore, this study aims to develop and validate a novel isocratic HPLC method with photodiode array detector for the analysis of rosmarinic acid contents in Boraginaceae and Lamiaceae family plants.

\section{MATERIALS AND METHODS}

\section{Materials}

Comfrey leaves, Rosemary leaves, Sage Leaves, Peppermint leaves and Java tea was obtained from local market in Yogyakarta Province, Indonesia. The solvent used in this research was pro analysis. Methanol p.a (Merck, Germany), Acetonitril p.a. (Merck. Germany), Aqua pro injection/ API (PT Ikapharmindo Putramas, Indonesia) and Formic acid (Merck, Germany). Rosmarinic acid standard was purchased from Phytolab, Germany.

\section{Instrumentation}

Analytical balance (VIBRA HT), High Performance Liquid Chromatography HPLC-0053 (Agilent, 
USA), Ultrasonic (Daihan, Korea), Zorbax Eclipse Plus C18 Analytical 4.6x150mm 5-micron (Agilent, USA) and micropipet 100-1000 $\mu \mathrm{l}$ (Thermo Scientific, USA).

\section{Extraction}

Each sample were diluted using methanol p.a. as a solvent in ratio 1:10. Extraction was carried using UAE methods in ultrasonic bath at $50^{\circ} \mathrm{C}$ for 50 minutes. The extracts of sample were filtered, the supernatant was separated and evaporated using water bath until get the thick extract.

\section{Standard solution preparation}

Standard solution was prepared for rosmarinic acid. Rosmarinic acid solution was made into a stock solution with concentration of $1 \mathrm{mg} / \mathrm{ml}$ prepared in 30\% acetonitrile. Series concentration of working solution were made by diluting the standard solution using $30 \%$ acetonitrile.

\section{Chromatography conditions}

Chromatography condition were supported with Zorbax Eclipse Plus C18 $(4.6 \times 150 \mathrm{~mm}, 5 \mu \mathrm{m})$ for stationary phase. The mobile phase used $30 \%$ acetonitrile and formic acid $(0,1 \% \mathrm{v} / \mathrm{v})$. The chromatography was set at isocratic mode and the flow rate $0,5 \mathrm{ml} / \mathrm{min}$. Wavelength detection was $330 \mathrm{~nm}$, injection volume $20 \mu \mathrm{l}$, temperature $30^{\circ} \mathrm{C}$ and run time was set at $15 \mathrm{~min}$.

\section{System suitability test}

System performance was check before the chromatographic runs. The tailing factor $(\mathrm{T})$ and theoretical plates $(\mathrm{N})$ are system suitability test variables.

\section{Linearity Test}

Linearity test was determined by using working standard solution of rosmarinic acid at series concentration (10-100 $\mu \mathrm{g} / \mathrm{ml})$. Each concentration was evaluated three times. Plotting the peak area against standard concentration produced the calibration curve. Data were evaluated for coefficients corelation $\left(\mathrm{R}^{2}\right)$ in linear regression method.

\section{Accuracy}

Percent recovery was the parameter of accuracy of the method. The accuracy was tested by adding a reference standard into sample. The total amount of $20 \mu \mathrm{l}$ of solution was injected in the chromatography system triplicate.

\section{Precision Test}

Determination of precision of the method using addition of rosmarinic acid standard into sample. A total of $20 \mu \mathrm{l}$ of solution was injected in the chromatography. The test was injected triplicate. Precision was evaluated as coefficient variance.

\section{Limit of detection (LOD) and limit of quantification (LOQ)}

LOD and LOQ under the proposed chromatography condition were evaluated by diluting the working standard solution to obtain the signal-to-noise $(\mathrm{S} / \mathrm{N})$ of analytes at 3:1 and 10:1 for LOD and LOQ, respectively.

\section{Determination of rosmarinic acid level}

Rosmarinic acid level was calculated for each sample. Sample were diluted in acetonitrile and $0,1 \%$ formic acid (30 \% v/v). Sample was filtered using $0,45 \mu \mathrm{m}$ membrane filter and homogenized before injected to chromatogram system.

\section{RESULTS AND DISCUSSION}

\section{System suitability test}

The specification of the method was assessed by peak purity using UV spectrum obtained from HPLC-DAD. The UV spectrum was recorded from $190 \mathrm{~nm}$ to $450 \mathrm{~nm}$ (Figure 1). At this study, rosmarinic acid detection used maximum wavelength at $330 \mathrm{~nm}$.

Recently, rosmarinic acid was detected using several mobile phase systems of isocratic and gradient HPLC. The HPLC system used acetonitrile-water and methanol-water in combination with phosphoric acid showed the best separation of rosmarinic acid ${ }^{6,14}$. However, rosmarinic acid detection takes a lengthy period due to its long retention time. The retention time of rosmarinic acid was greater than 20 minutes on a gradient HPLC system. Meanwhile, rosmarinic acid was captured after 20 minutes using a mobile phase combination of methanol-water and formic $\operatorname{acid}^{15}$. On the other hand, mobile phase combination of acetonitrile-water revealed a fast retention time within 5 minutes but the recent study used $60 \%$ of acetonitrile in isocratic condition at flow rate of $1,5 \mathrm{ml} / \mathrm{min}^{16}$. The recent study needs some improvement such as efficiency of solvent use as mobile phase. At this study, chromatogram of rosmarinic acid showed the fast retention time within 6 minutes with $30 \%$ of acetonitrile-water in combination with formic acid at flow rate of $0,5 \mathrm{ml} / \mathrm{min}$ (Figure 2). It showed efficiency in using solvent of mobile phase.

In the system suitability test, the standard solution of rosmarinic acid with a flow rate $0,5 \mathrm{ml} / \mathrm{min}$ was injected $20 \mu \mathrm{l}$ at a concentration of 0,20 $\mathrm{mg} / \mathrm{ml}$. The test result showed the theoretical plates and tailing factor are in accordance with the literature specification ${ }^{12}$. Table 1 reports the research of the system suitability test.

\section{Linearity test}

The linearity test is occurred to explain the correlation of response and concentration. Linearity is showed by coefficient determination $\left(\mathrm{R}^{2}\right)$ that closes to 1 . The linearity of method was met the parameter with $\mathrm{R}^{2}$ of 0,987 (Figure 4). As a result, it is possible to conclude that the approach generates a linear response to rosmarinic acid concentrations.

\section{Accuracy and Precision test}

The accuracy and precision test are investigated by the standard enumeration method which is to add a reference standard into the sample. This method was chosen since it is unable to construct a sample matrix without the presence of analyte ${ }^{17}$. The method's calculated value's similarity to the nominal concentration of the analyte proved the accuracy of an analytical method (expressed in percentage). The

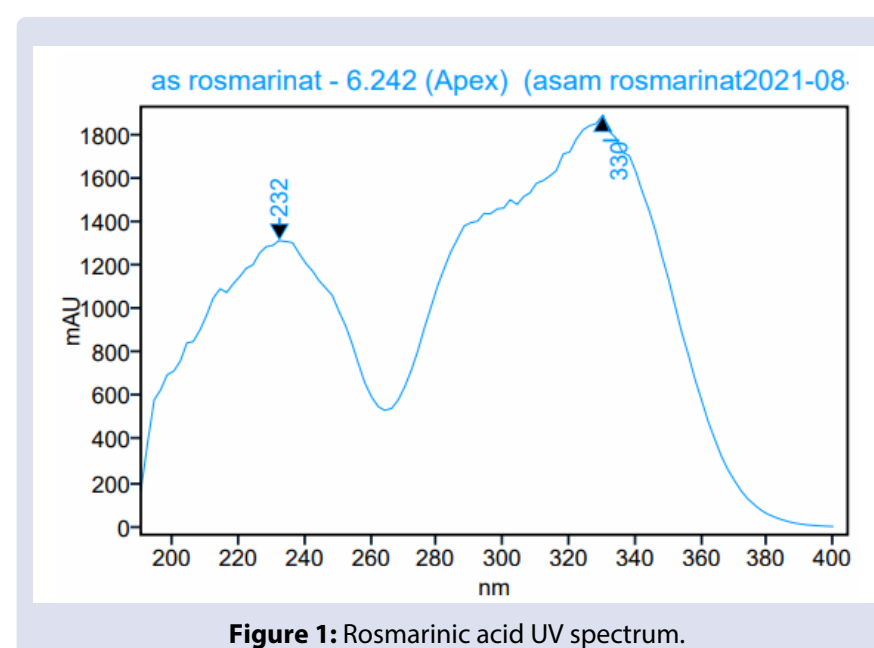

Figure 1: Rosmarinic acid UV spectrum. 


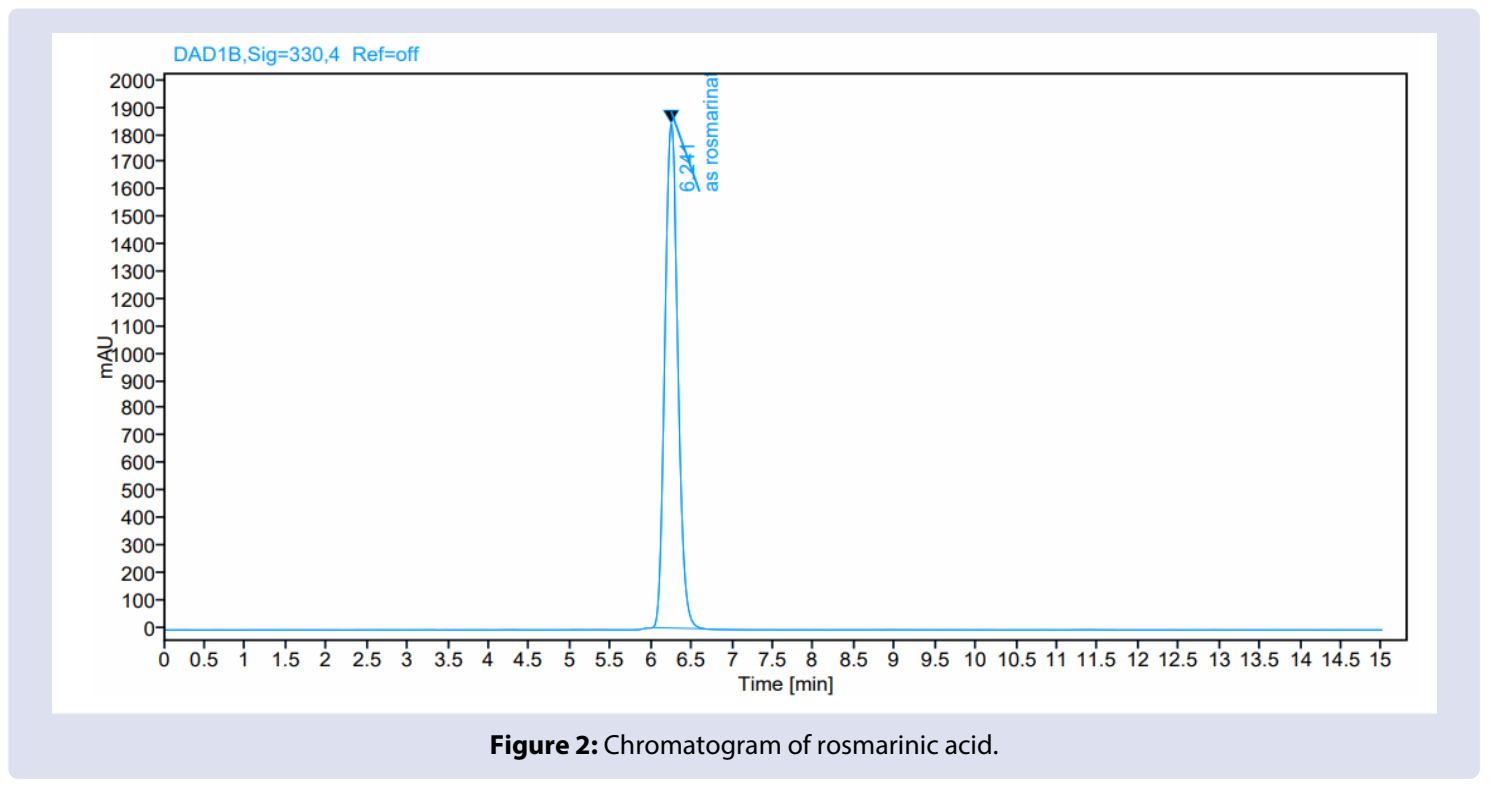

Table 1: System suitability test of rosmarinic acid.

\begin{tabular}{lccc}
\hline & Tailing Factor & Theoritical Plats & Repeatability (RSD, $\mathrm{n}=6$ ) \\
\hline Standard & 1,22 & 9963,33 & 0,02 \\
Literature specification & $<2$ & $>2000$ & $<1 \%$
\end{tabular}

Table 2: Accuracy test of rosmarinic acid.

\begin{tabular}{|cccc|}
\hline Rosmarinic acid standard & Theorotical $(\mu \mathrm{g} / \mathrm{ml})$ & Found $(\mu \mathrm{g} / \mathrm{ml})$ & Recovery $(\%)$ \\
\hline 1 & 2,020 & 1,941 & 96,095 \\
2 & 2,020 & 1,992 & 98,626 \\
3 & 2,020 & 2,187 & 108,279 \\
\hline
\end{tabular}

Table 3: Presicion test of Rosmarinic acid.

\begin{tabular}{|ccc|}
\hline Reference standard & Intra-day precision & Inter-day precision \\
\hline Rosmarinic acid & $6,37 \%$ & $3,46 \%$ \\
\hline
\end{tabular}

\section{Table 4: Validation method parameter.}

\begin{tabular}{cc}
\hline Parameter & Rosmarinic acid \\
\hline Regression equation & $\mathrm{y}=83,82 \mathrm{x}+977,62$ \\
Coefficient corelation $\left(\mathrm{R}^{2}\right)$ & 0,9866 \\
Linearity range & $1-100 \mu \mathrm{g} / \mathrm{ml}$ \\
LOD & $14,19 \mu \mathrm{g} / \mathrm{ml}$ \\
LOQ & $43,00 \mu \mathrm{g} / \mathrm{ml}$ \\
\hline
\end{tabular}

Table 5: Determination of rosmarinic acid in various plant extracts.

\begin{tabular}{|c|c|c|c|c|c|}
\hline \multirow{2}{*}{ Extracts sample } & \multicolumn{3}{|c|}{ Rosmarinic acid level ( $\mu \mathrm{g} / \mathrm{g})$} & \multirow{2}{*}{ Mean } & \multirow{2}{*}{ SD } \\
\hline & 1 & 2 & 3 & & \\
\hline Symphytum officinale & 0,169 & 0,167 & 0,170 & 0,169 & 0,068 \\
\hline Rosmarinus officinalis & 8,599 & 8,568 & 8,616 & 8,594 & 0,598 \\
\hline Mentha piperita & 0,189 & 0,189 & 0,190 & 0,190 & 0,023 \\
\hline Orthosiphon stamineus & 0,454 & 0,353 & 0,242 & 0,350 & 5,295 \\
\hline Salvia officinale & 0,052 & 0,080 & 0,051 & 0,061 & 0,413 \\
\hline
\end{tabular}

result showed in Table 2 that the recovery at the addition of $100 \%$ rosmarinic acid were $101,00 \pm 6,43 \%(n=3)$.

The analytical method's precision indicates the consistency of repeated individual analyte determinations. The coefficient of variation is used to express precision (CV). The result showed that the CV values in intraday at the addition of $100 \%$ rosmarinic acid was $6,37 \%(n=3)$ and the inter-day was $3,46 \%(n=3)$. The precision test showed in Table
3. According to the International Conference on Harmonization, this suggested technique meets the accuracy and precision requirements ${ }^{18}$.

Limit of detection (LOD) and limit of quantification (LOQ)

The results of rosmarinic acid validation parameter describe in Table 4. The LOD and the LOQ were less than $14,19 \mu \mathrm{g} / \mathrm{mL}$ and $43,00 \mu \mathrm{g} /$ 
a

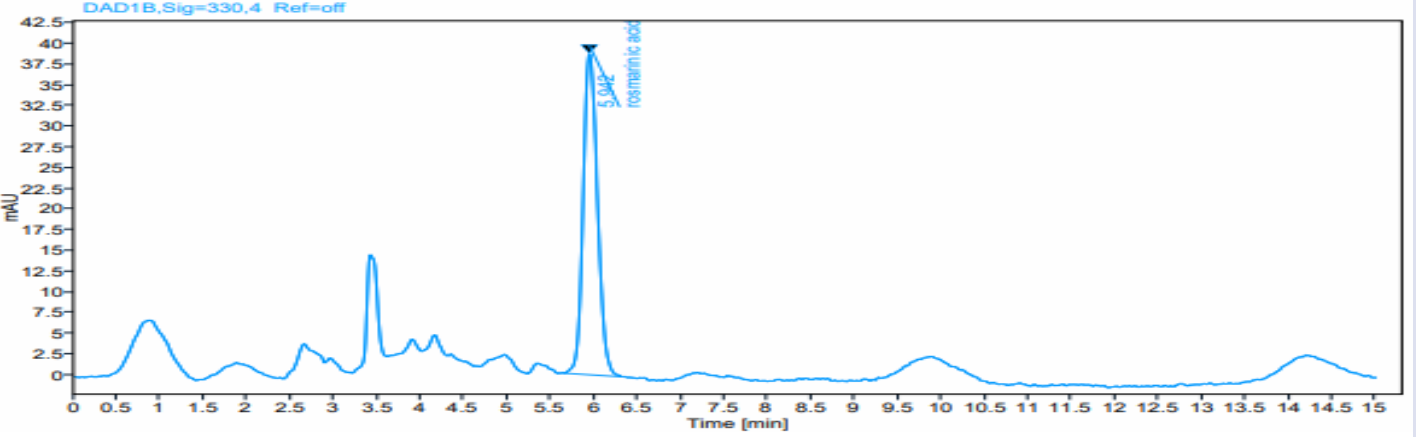

b

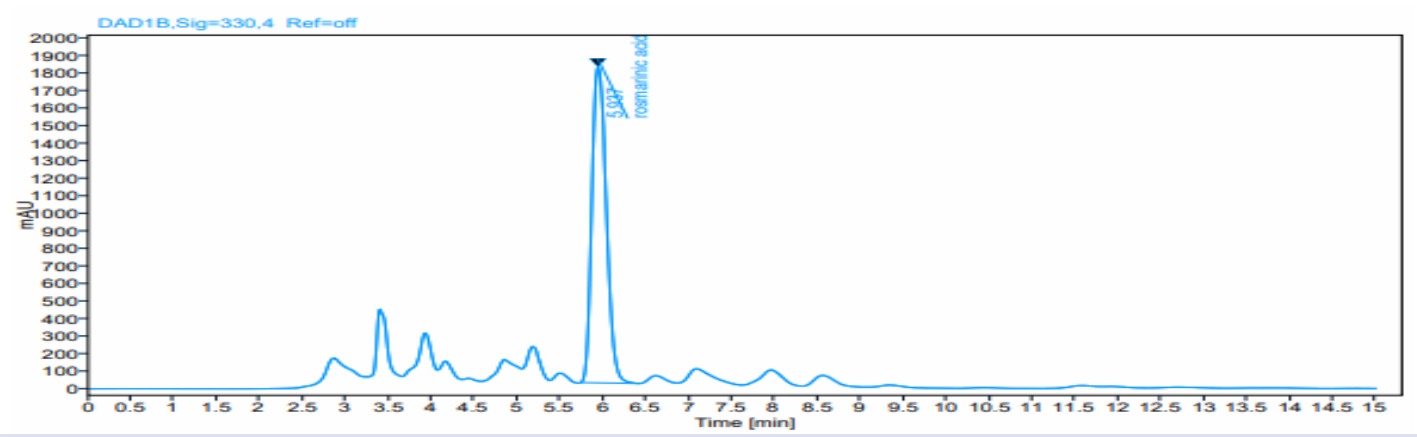

c

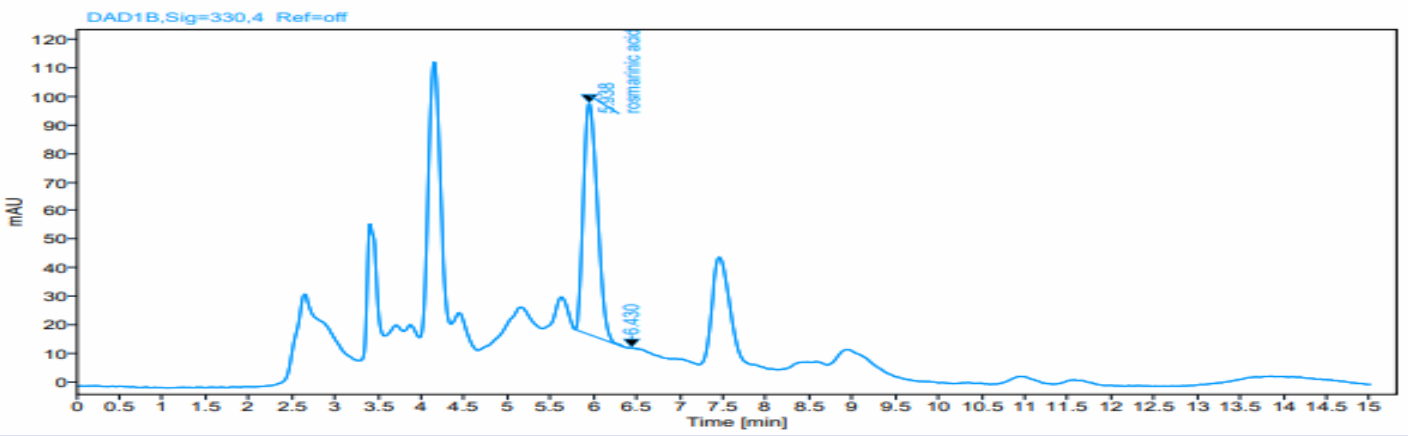

d

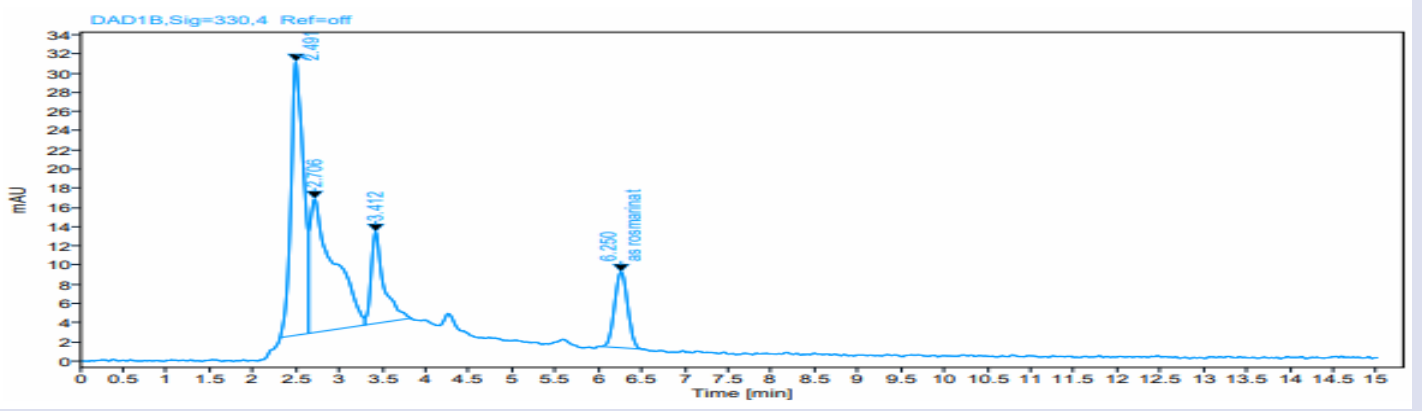

e

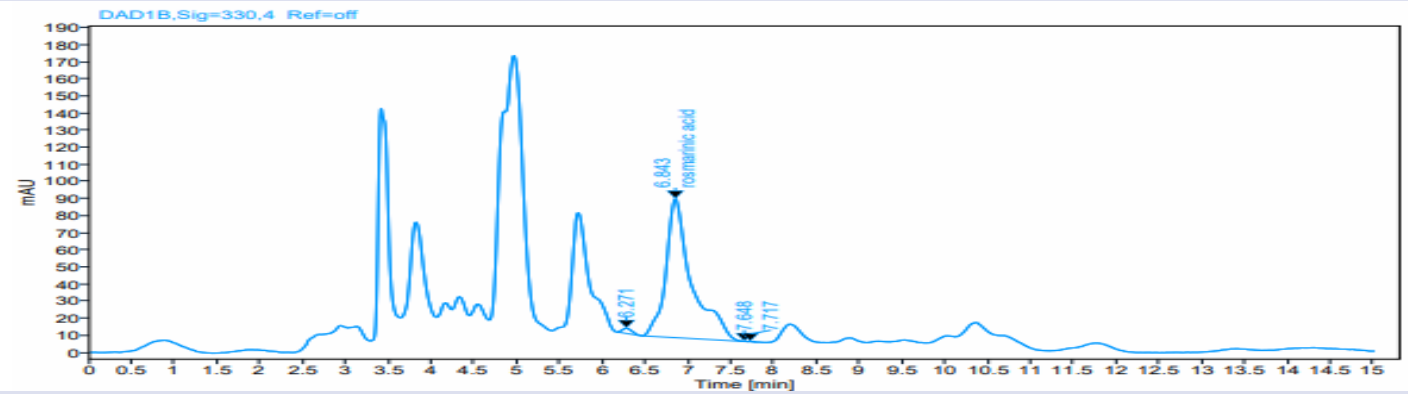

Figure 3: Chromatogram of, Symphytum officinale (a), Rosmarinus officinalis (b), Mentha piperita (c), Orthosiphon stamineus (d) and Salvia officinale (e). 


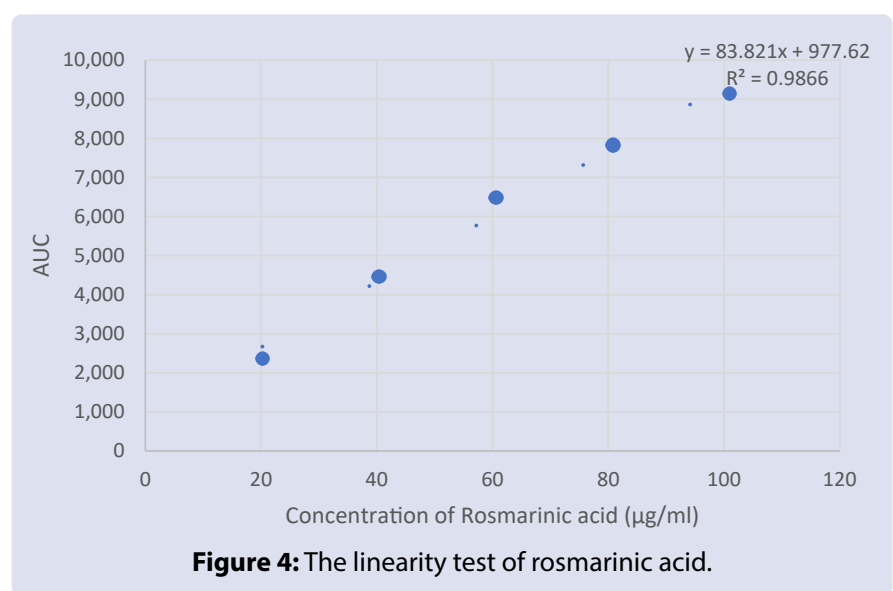

$\mathrm{mL}$ rosmarinic acid, respectively. The limitations are low enough to determine rosmarinic acid, as would be seen from these results.

\section{Quantification of rosmarinic acid in various plants}

The ratio of peak area values was used to quantify rosmarinic acid in every case. The yield of the extract and the weight of the plants were used to estimate the amount of rosmarinic acid in the extract. The test was performed three times. Table 5 showed the rosmarinic acid level in Rosmarinus officinalis, Symphytum officinale, Mentha piperita, Orthosiphon stamineus and Salvia officinale. The analyses were run under the validated condition that have describe above. Rosmarinus officinalis has the highest level of rosmarinic acid. Rosmarinic acid level in Rosmarinus officinalis was $8,599 \mu \mathrm{g} / \mathrm{gram}$ dry weight. Ultrasound assisted extraction (UAE) help to extract rosmarinic acid in plants. Methanol extract rosmarinic acid higher than water. It proved the HPLC method above suitable to quantified rosmarinic acid ${ }^{6}$. Rosmarinus officinalis was known as rosemary. It has been used as flavouring herbs and folk medicine ${ }^{19}$. The previous study and this study have similarity of rosmarinic acid level ${ }^{5,20-22}$. Harvesting time, climate and regional condition contribute to difference amount of rosmarinic $\operatorname{acid}^{23}$.

On the previous study, rosmarinic acid level of Symphytum officinale root was $7,557 \mathrm{mg} / \mathrm{gram}$ and it has been extracted using reflux ${ }^{3}$. The result of this study was different with the previous because this study used the leaves part of Symphytum officinale. Beside that, the amount of rosmarinic acid content is affected by the extraction procedure. On Mentha piperita, Salvia officinale and Orthosiphon stamineus has been reported contain rosmarinic acid 28,3 mg/g, 39,3 mg/g and 9,10 mg/g respectively ${ }^{24,25}$. Solvent, extraction method and pretreament of sample effect the capacity of rosmarinic acid extraction ${ }^{25,26}$.

\section{CONCLUSION}

This method is simple, sensitive and valid enough to analyse rosmarinic acid in Rosmarinus officinalis, Symphytum officinale, Mentha piperita, Orthosiphon stamineus and Salvia officinale. The approach is regarded to be appropriate for quick routine analysis.

\section{ACKNOWLEDGEMENTS}

The authors would like to acknowledge a research funding from the Republic of Indonesia's Ministry of Research, Technology, and Higher Education, contract number NKB-374/UN2.RST/HKP.05.00/2021.

\section{REFERENCES}

1. Sik B, Hanczné EL, Kapcsándi V, Ajtony Z. Conventional and nonconventional extraction techniques for optimal extraction processes of rosmarinic acid from six Lamiaceae plants as determined by HPLC-DAD measurement. J Pharm Biomed Anal. 2020;184. doi:10.1016/j.jpba.2020.113173

2. Oliviu Vostinaru, Simona Conea, Cristina Mogosan, Claudia Crina Toma, Corina Claudia Borza LV. Anti-inflammatory and antinociceptive effect of Symphytum officinale root. Rom Biotechnol Lett. 2017; (x).

3. Trifan A, Opitz SEW, Josuran $\mathrm{R}$, et al. Is comfrey root more than toxic pyrrolizidine alkaloids? Salvianolic acids among antioxidant polyphenols in comfrey (Symphytum officinale L.) roots. Food Chem Toxicol. 2018;112(November 2017):178-187. doi:10.1016/j. fct.2017.12.051

4. Gonçalves GA, Corrêa RCG, Barros L, et al. Effects of in vitro gastrointestinal digestion and colonic fermentation on a rosemary (Rosmarinus officinalis $L$ ) extract rich in rosmarinic acid. Food Chem. 2019;271(July 2018):393-400. doi:10.1016/j.foodchem.2018.07.132

5. Jurić $T$, Mićić $N$, Potkonjak $A$, et al. The evaluation of phenolic content, in vitro antioxidant and antibacterial activity of Mentha piperita extracts obtained by natural deep eutectic solvents. Food Chem. 2021;362(May). doi:10.1016/j.foodchem.2021.130226

6. Öztürk N, Tunçel M, Uysal UD, Oncu-Kaya EM, Koyuncu O. Determination of Rosmarinic Acid by High-Performance Liquid Chromatography and Its Application to Certain Salvia Species and Rosemary. Food Anal Methods. 2011;4(3):300-306. doi:10.1007/ s12161-010-9164-2

7. de Torre MP, Cavero RY, Calvo MI, Vizmanos JLW. A simple and a reliable method to quantify antioxidant activity in vivo. Antioxidants. 2019;8(5):1-11. doi:10.3390/antiox8050142

8. Petersen M, Simmonds MSJ. Rosmarinic acid. Phytochemistry. 2003;62(2):121-125. doi:10.1016/S0031-9422(02)00513-7

9. Zakerin S, Hajimehdipoor H, Mortazavi SA, Choopani R, Sabetkasaei M, Tavakolifar F. A Validated HPLC Method for Quantitation of Rosmarinic Acid in a Polyherbal Syrup. 2020;7(2):5-11. doi:10.22127/ rjp.2019.205478.1527

10. Salehi B, Sharopov F, Tumer TB, et al. Symphytum species: A comprehensive review on chemical composition, food applications and phytopharmacology. Molecules. 2019;24(12):1-33. doi:10.3390/ molecules24122272

11. Choi SH, Jang GW, Choi S II, et al. Development and validation of an analytical method for carnosol, carnosic acid and rosmarinic acid in food matrices and evaluation of the antioxidant activity of rosemary extract as a food additive. Antioxidants. 2019;8(3). doi:10.3390/ antiox8030076

12. Couto RO, Conceição EC, Chaul LT, et al. Validated HPLC-PDA method for rosmarinic acid quantification in rosemary. Lat Am J Pharm. 2011;30(10):1951.

13. Cai X, Yang F, Zhu L, Xia Y, Wu Q, Xue H. molecules Rosmarinic Acid, the Main E ff ective Constituent of Orthosiphon stamineus, Inhibits Intestinal Epithelial.

14. Wang H, Provan GJ, Helliwell K. Determination of rosmarinic acid and caffeic acid in aromatic herbs by HPLC. Food Chem. 2004;87(2):307-311. doi:10.1016/j.foodchem.2003.12.029

15. Hussain MH. Fast High Performance Liquid Chromatography and Ultraviolet Method for Determination of Phenolic Antioxidants in Fresh. J Nat Sci Res. 2015;5(17):89-93.

16. Yantih N, Methananda A, Harahap Y, Sumaryono W, Rahayu L. Validation of high-performance liquid chromatography for determination of bromelain in pineapple (Ananas comosus (L) Merr) Water. Pharmacogn J. 2019;11(5):901-906. doi:10.5530/ pj.2019.11.144

17. International Conference on Harmonisation. International Conference on Harmonisation. Valid Anal Proced text Methodol Q2. 2014;2(June 1995):1070-1072. doi:10.1016/B978-0-12-3864543.00861-7 
18. Li P Liu A Li Y, et al. Development and validation of an analytical method based on HPLC-ELSD for the simultaneous determination of rosmarinic acid, carnosol, carnosic acid, oleanolic acid and ursolic acid in rosemary. Molecules. 2019;24(2):1-8. doi:10.3390/ molecules 24020323

19. Chemistry P, Sciences P. Simultaneous Analysis of Bioactive Markers from Orthosiphon Stamineus Benth Leaves Extracts by Reverse Phase High Performance Liquid Chromatography Mohammad Jamshed Ahmad Siddiqui * and Zhari Ismail. 2011;10(April 2010):97-103.

20. Dresler S, Szymczak G, Wójcik M. Comparison of some secondary metabolite content in the seventeen species of the boraginaceae family. Pharm Biol. 2017:55(1):691-695. doi:10.1080/13880209.20 16.1265986

21. Mansinhos I, Gonçalves S, Rodríguez-Solana R, Ordóñez-Díaz JL, Moreno-Rojas JM, Romano A. Ultrasonic-assisted extraction and natural deep eutectic solvents combination: A green strategy to improve the recovery of phenolic compounds from lavandula pedunculata subsp. lusitanica (chaytor) franco. Antioxidants. 2021;10(4). doi:10.3390/antiox10040582
22. Hassanzadeh K, Aliniaeifard S, Farzinia MM, Ahmadi M. Effect of Phenological Stages on Essential Oil Content, Composition and Rosmarinic Acid in Rosmarinus officinalis L. Int J Hortic Sci Technol. 2017;4(2):251-258. doi:10.22059/ijhst.2017.234339.194

23. Shekarchi M, Hajimehdipoor $H$, Saeidnia S, Gohari AR, Hamedani MP. Comparative study of rosmarinic acid content in some plants of Labiatae family. Pharmacogn Mag. 2012;8(29):37-41. doi:10.4103/0973-1296.93316

24. Abdullah S, Shaari AR, Rukunudin IH, Ahmad MS. Effect of Drying Temperature on Rosmarinic Acid and Sinensetin Concentration in Orthosiphon stamineus Herbal Leaves. IOP Conf Ser Mater Sci Eng. 2018;318(1). doi:10.1088/1757-899X/318/1/012074

25. Angelov G, Penchev P, Condoret JS. Extraction of rosmarinic acid from botanicals with supercritical carbon dioxide. Effect of the modifiers added to the solvent. Comptes Rendus L'Academie Bulg des Sci. 2011;64(7):953-958.

\section{GRAPHICAL ABSTRACT}<smiles>O=C(/C=C/c1ccc(O)c(O)c1)OC(Cc1ccc(O)c(O)c1)C(=O)O</smiles>

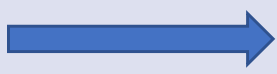

Quantification of Rosmarinic acid

\begin{tabular}{|l|l|}
\hline $\begin{array}{l}\text { Rosmarinus } \\
\text { officinalis }\end{array}$ & \\
\hline $\begin{array}{l}\text { Symphytum } \\
\text { officinale }\end{array}$ & \\
\hline Mentha & \\
piperita & \\
officinale & \\
\hline Stamineus & \\
\hline Orthosiphon & \\
\hline
\end{tabular}

- Mobile phase was $30 \%$ acetonitrile

- Flow rate was $0,5 \mathrm{ml} / \mathrm{min}$.
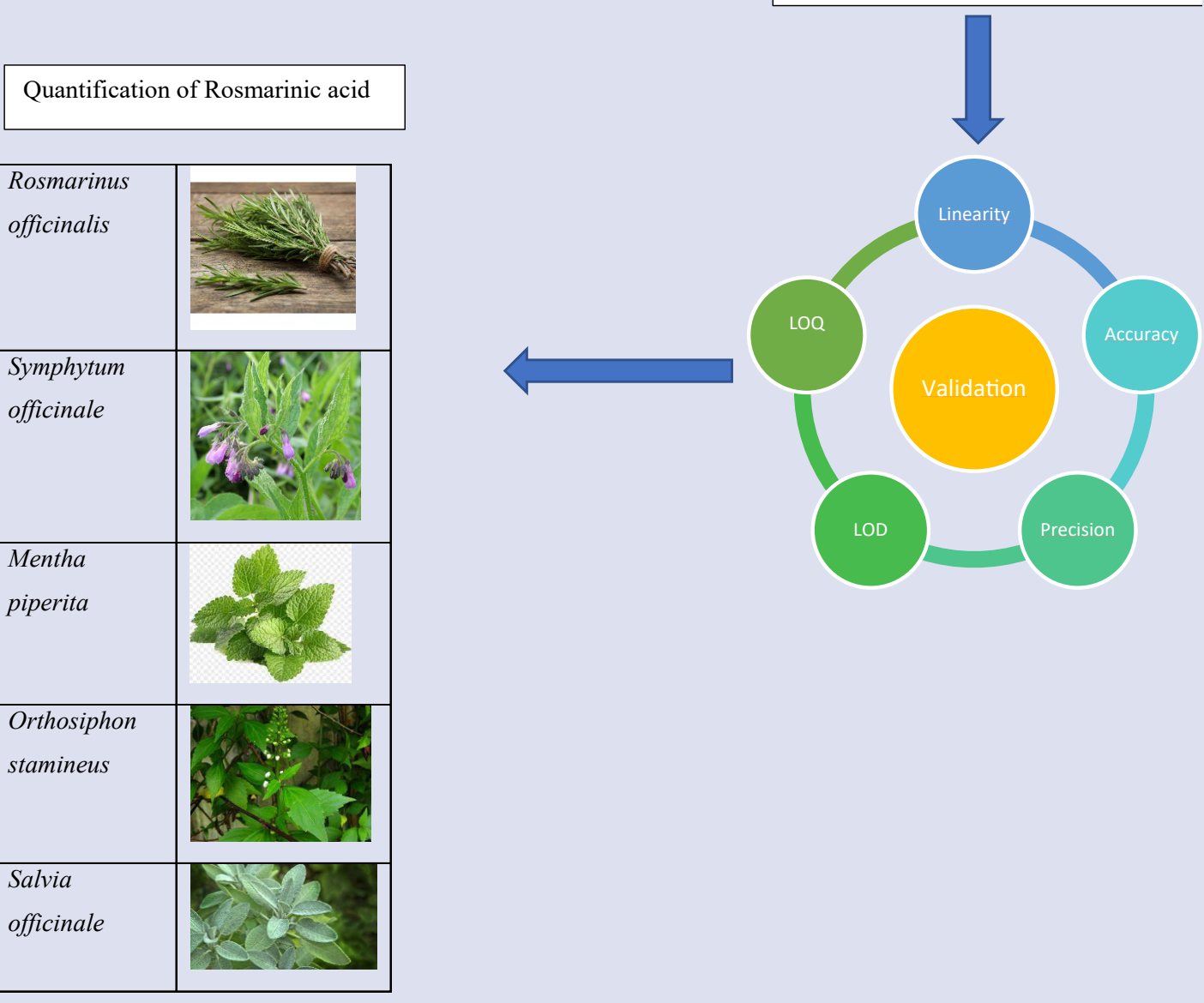


\section{ABOUT AUTHORS}

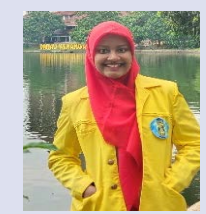

Andiri Niza Syarifah is Pharmacist and Magister Pharmacy Student at Faculty of Pharmacy, Universitas Indonesia. The Master research focused on Natural Deep Eutectic Solvent (NADES), development of extraction and analytical method.

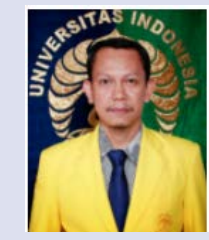

Herman Suryadi is Lecturer and Head of Laboratory of Microbiology and Biotechnology, Faculty of Pharmacy, Universitas Indonesia. His research focused on Bioprocess, Biotechnology and Pharmaceutical Chemistry.

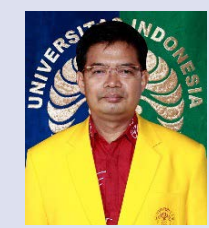

Abdul Mun'im is an Associate Professor at Department Pharmaceutical Sciences, Faculty of Pharmacy, Universitas Indonesia. His research focused on Pharmacognosy and Phytochemistry, drugs discovery of herbal plants, extraction technology, metabolite profiling and structure elucidation.

Cite this article: Syarifah AN, Suryadi H, Mun'im A. Validation of Rosmarinic Acid Quantification using High-Performance Liquid Chromatography in Various Plants. Pharmacogn J. 2022;14(1): 165-171. 